\title{
Relação Precipitação-Deslizamento no Município de São Bernardo do Campo - SP
}

\author{
Precipitation-landslide relation in the city of São Bernardo do Campo - SP
}

\author{
Ellen A. N. Molina ${ }^{1}$, Andréa O. Cardoso² e Fernando R. Nogueira ${ }^{3}$ \\ ${ }^{1,2,3}$ Centro de Engenharia, Modelagem e Ciências Sociais Aplicadas, Universidade Federal do ABC , UFABC, São \\ Paulo - Brasil
}

\begin{abstract}
Resumo
Em países tropicais como o Brasil, um dos principais fatores deflagradores de movimentos de massa é o volume de água infiltrado. A análise desta relação tem sido cada vez mais explorada, com o objetivo de dar subsídios técnicos para a tomada de decisão aos municípios e, assim, evitar desastres naturais. Este trabalho analisa essa relação em uma região de São Bernardo do Campo - São Paulo, através de gráficos de acumulados de precipitação relacionados com ocorrência de deslizamentos, denominados envoltórias. Dados históricos de precipitação e de ocorrências de deslizamentos, no período de 2003 a 2012, foram analisados, oriundos de coleta realizada pela Prefeitura no ponto de Vila do Tanque e toda sua região homogênea. Os resultados do estudo permitiram a obtenção de envoltórias ajustadas para diferentes critérios analisados de limiares de precipitação, sendo identificado o melhor critério correspondente ao acumulado de quatro dias (50mm em 1 dia e $150 \mathrm{~mm}$ em quatro dias), considerado mais restritivo, o qual apresentou uma boa representação da curva de ocorrência de deslizamentos relacionada a precipitação. Em adição, destacou-se a dificuldade de se definir limiares de precipitação para o desencadeamento de deslizamentos, principalmente em áreas urbanas com grande interferência antrópica, potencializando situações de risco.
\end{abstract}

Palavras-chave: Precipitação. São Bernardo do Campo. Deslizamentos.

\begin{abstract}
In tropical countries like Brazil, one of the main trigger factors of mass movements is the volume of infiltrated water. Analysis of this relation has been increasingly explored with the aim of providing technical support for decision making to municipalities in order to avoid natural disasters. This paperwork examines this relation in a region of São Bernardo do Campo - São Paulo, through graphs of accumulated precipitation related to landslides registers, called "envoltórias". Historical data of rainfall and landslide occurrences from 2003 to 2009 was analyzed, through collection held by the city hall at the point of Vila do Tanque and all its homogeneous region. This study results allowed to obtain "envoltórias" adjusted to the different criteria analyzed of precipitation thresholds, identified the best corresponding to the cumulative four-day (50 $\mathrm{mm}$ in 1 day and $150 \mathrm{~mm}$ in four days) criteria, more restrictive, which showed a good representation of the occurrence of landslides related to precipitation. In addition, the highlight was the difficultyof defining the rainfall limit for triggering landslides, especially in urban areas with large anthropic interference potentiating risk situations.
\end{abstract}

Keywords: Precipitation. São Bernardo do Campo. Landslides. 


\section{Introdução}

Os movimentos de massa gravitacionais se destacam na região Sudeste dentre os eventos perigosos, os quais são processos naturais de transporte de massas pela gravidade devido à dinâmica geomorfológica das encostas, mas que, em grande parte das ocorrências, são agravados e acelerados pelas interferências antrópicas e condições climáticas. A magnitude dos movimentos de massa está associada a fatores estruturais, relevo, solo e cobertura vegetal.

Em países tropicais como o Brasil, um dos principais fatores deflagradores de movimentos de massa é o volume de água infiltrado. Tal relação pode ser explorada para fins prognósticos. Guidicini e Iwasa (1976) estudaram nove regiões do território nacional com casos de precipitação intensa e histórico de ocorrências de deslizamento, sendo obtidos resultados para a previsibilidade de ocorrência de deslizamentos com cartas de periculosidade.

Estudo de deslizamentos registrados durante 30 anos na Serra do Mar, na região de Cubatão, indicaram a chuva acumulada de 4 dias como determinante ao processo de deslizamento (Tatizana et al., $1987 \mathrm{a}, \mathrm{b}$ ).

Elbachá et al. (1992) analisou a influência da chuva para a cidade de Salvador, concluindo que esta influência é responsável pela maioria dos episódios de escorregamento, com um limite indicativo de $120 \mathrm{~mm}$ para 4 dias acumulados de precipitação.

Ide (2005) correlacionou precipitação e deslizamentos na região de Campinas, destacando a influência e a importância da análise da precipitação acumulada em 7 e 5 dias para diferentes características geológicas.

Na região litorânea de Angra dos Reis, Soares (2006) caracterizou a relação da sazonalidade da precipitação com os eventos de deslizamento, sendo aplicada a metodologia de Tatizana et al. (1987 a, b) para diversos critérios, destacando-se o acumulado de 2 dias, os quais representam melhor a relação. A Fundação Instituto de Geotécnica - Geo-Rio, órgão da Secretaria Municipal de Obras do Rio de Janeiro, aplica desde o ano de 2000 este método de Tatizana et al. (1987 a, b) no Estado para implantação do nível de alerta utilizando a precipitação acumulada de 4 dias.

Em análise de correlação de precipitação e deslizamentos para encostas urbanas de Ouro Preto - MG, Castro (2006) concluiu que 5 dias de chuva acumulada é a que mais influencia na deflagração dos escorregamentos.

Há indícios de que eventos de precipitação em grandes centros urbanos apresentam uma tendência à ocorrência de chuvas mais intensas em períodos mais curtos, sendo importante o desenvolvimento de estudos de impactos da precipitação. Tal tendência foi identificada por Silva Dias et al. (2013) através de análise histórica da precipitação no município de São Paulo, no período de 1931 a 2010. Como conclusão deste estudo, os processos urbanos, relacionados com ilhas de calor e poluição, podem, em parte, explicar os eventos extremos de precipitação, somados aos padrões de variabilidade climática.

As precipitações assumem papel de agente de ação progressiva e agente de ação instantânea nos fenômenos de instabilidade de taludes. A ação progressiva, por exemplo, produz alterações da densidade do solo, diminuindo a coesão e aumentando o peso do solo, diminuindo a resistência ao cisalhamento (SOARES, 2006).

A Região Metropolitana de São Paulo possui peculiaridades hidrometeorológicas próprias, e seu desenvolvimento urbano em áreas inadequadas gera maiores ocorrências de eventos perigosos (VALVERDE; CARDOSO, 2012). A caracterização da climatologia local e a identificação dos valores de chuva, que podem desencadear eventos danosos à população, são de grande valia aos municípios para geração de Planos Preventivos.

Faceto et al. (2012) avaliou a relação da climatologia da precipitação e as ocorrências médias de deslizamentos no período de 1997 a 2011 em São Bernardo do Campo $\mathrm{SP}$, tendo observado que os meses de máxima e mínima precipitação são acompanhados pelos maiores e menores registros de eventos de deslizamentos, respectivamente. Ficou evidente a sazonalidade na distribuição de precipitação e deslizamentos, demonstrando que os períodos mais críticos para deslizamentos ocorrem em épocas chuvosas, principalmente nos meses de verão, sendo o oposto verificado para o inverno. Os autores observaram que o aumento do número de eventos de deslizamento de dezembro para janeiro é muito mais expressivo do que aumento na precipitação, evidenciando a importância da saturação do solo e, consequentemente, a redução de seus parâmetros de resistência (coesão e ângulo de atrito), devido à ocorrência de chuvas nos meses anteriores ao mês de janeiro.

O município de São Bernardo do Campo, município do Grande ABC, com área total de $408,45 \mathrm{~km}^{2}$, está localizado na mesorregião Metropolitana de São Paulo e microrregião de São Paulo. Sua população, de acordo com Censo do IBGE de 2010, é de 765.203 habitantes.

Dado que a precipitação é um fator importante para a ocorrência de deslizamentos, e que a cidade de São Bernardo do Campo (SBC) apresenta grande suscetibilidade aos processos geodinâmicos, devido aos seus compartimentos geomorfológicos (IPT,1990), o presente trabalho tem como objetivo estudar a influência da precipitação acumulada na indução de deslizamento em SBC, buscando identificar os limiares críticos de precipitação associados às maiores ocorrências de deslizamentos.

\section{Desenvolvimento do Trabalho}

\subsection{Dados e Metodologia}

Foram utilizados dados históricos de precipitação contendo informações com três leituras ao dia, e dados diários de ocorrências de movimentos de massa, ambos no período de 2003 a 2012, fornecidos pela Defesa Civil 
do Município.

Como área de estudo, selecionou-se o posto de coleta de precipitação situado na Vila do Tanque, o qual, em análise do IPT (1999), é a área que apresenta o total mensal de precipitação mais relevante dentre os outros pontos de coleta, e seu entorno possui grande vulnerabilidade, com presença de assentamentos precários, áreas não consolidadas e ocupação diversificada. Este posto localiza-se próximo aos bairros Montanhão, Ferrazópolis, Demarchi, Santa Terezinha e Botujuru, que foram considerados como região homogênea, devido, principalmente, à sua característica geomorfológica semelhante. De acordo com IPT (1999), as áreas de risco de escorregamento mais problemáticas do município se encontram nesta região do complexo Montanhão, que forma um conjunto de morros com encostas de alta declividade, topos estreitos e alongados, e vales fechados. Desse modo, os dados de pluviometria coletados no ponto Vila do Tanque também foram aplicados aos bairros citados. A Figura 1 apresenta a localização do ponto de coleta dos dados de precipitação e os bairros analisados.
Para análise dos dados, realizou-se primeiramente a separação dos dados relacionados a movimentos de massa gravitacionais. Posteriormente, tais episódios foram agregados em regiões definidas pelos bairros oficiais, pois as informações obtidas estavam para as microrregiões, as subdivisões dos bairros de SBC. Nessa agregação, considerou-se como um dia de ocorrência se em algum local do bairro houve tal registro.

As séries de precipitação passaram por diversos tratamentos. Foi necessário gerar o acumulado diário, já que a coleta nos pluviômetros no município é realizada três vezes ao dia. No entanto, houve diversos dados faltantes, os quais impossibilitaram o uso do dado diário e dos próximos dias, pois poderiam resultar em inconsistência nos resultados da análise, que considerará o acumulado em mais de um dia. Desse modo, os dias com dados faltantes foram excluídos e não considerados, assim como todos os dias impactados ao acumular os dados em períodos de dias consecutivos. Assim, foi gerado um novo conjunto de dados, considerando somente os eventos com chuva, utilizado como base para a aplicação dos métodos de análise.

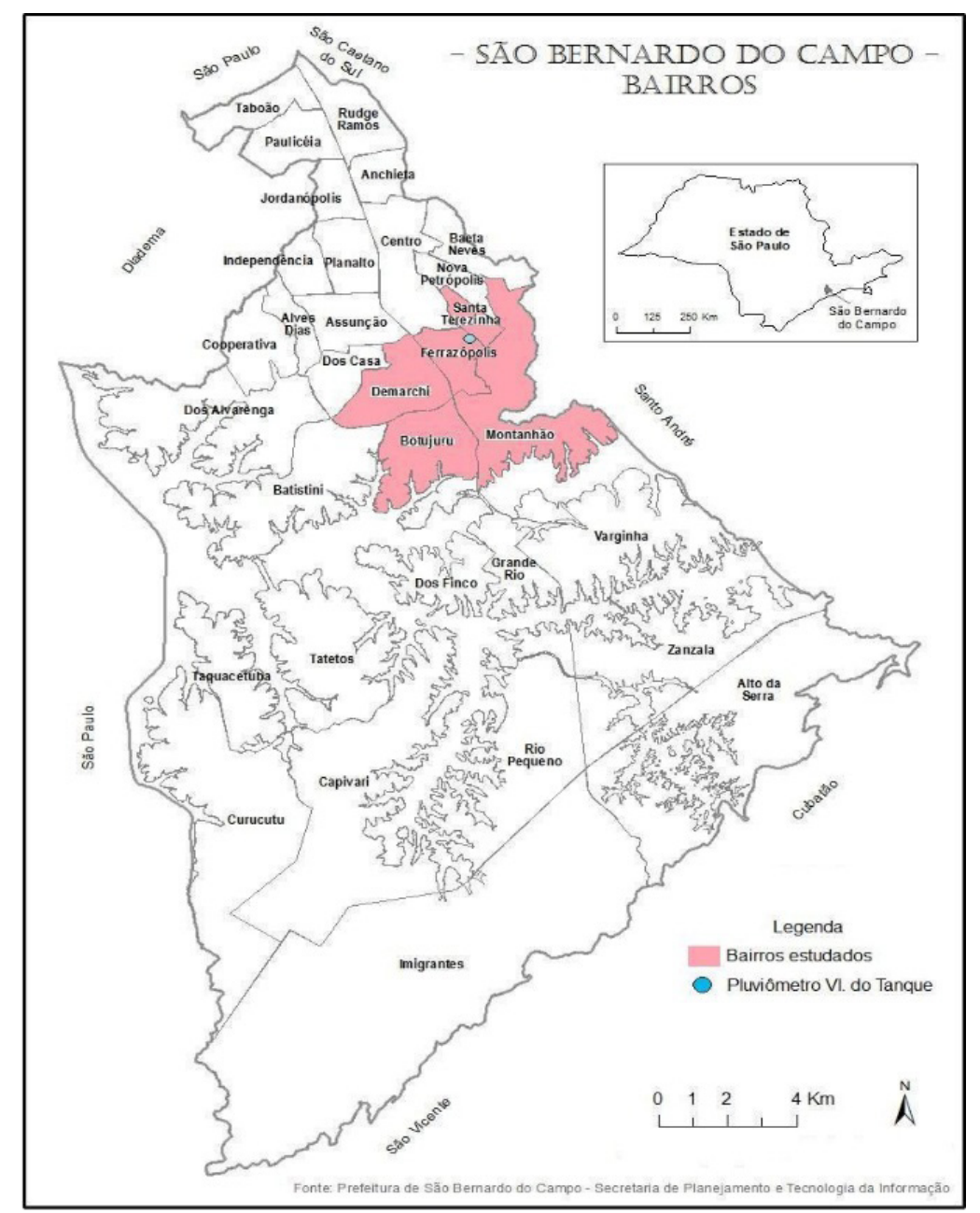

Figura 1 - Município de São Bernardo do Campo, com destaque para os bairros estudados e a localização do pluviômetro Vila do Tanque. Imagem adaptada (PMSBC, 2013) 
Visando conhecer o regime de precipitação da região, foi realizada uma análise climatológica, obtendo-se médias da precipitação acumulada mensal no período estudado. Em adição, para classificar a distribuição de precipitação diária em categorias de cada mês, foram identificados os limiares de precipitação diária através da técnica dos quantis (XAVIER; XAVIER, 1987), considerando somente os dias com chuva e classificando conforme os limiares de precipitação associada, sendo: muito seco se o quantil $\mathrm{q} \leq 0,15$; seco se $0,15<\mathrm{q} \leq 0,35$; normal se $0,35<\mathrm{q} \leq 0,65$; chuvoso se $0,65<\mathrm{q} \leq 0,85$; e muito chuvoso se $\mathrm{q}>0,85$. Este método está relacionado com o princípio da relativização estatística, em que é possível interpretar de forma adequada o significado de um total pluviométrico (XAVIER; XAVIER, 1987).

Para relacionar a precipitação com os eventos de deslizamento, foi aplicada a metodologia dos gráficos de envoltórias às séries de dados diários tratados, onde são conjugados os valores acumulados de precipitação em um dia com a precipitação acumulada em dias antecedentes, sendo considerado o acumulado de dois, três e quatro dias consecutivos. Para isso, foram construídas séries de precipitação somando os totais registrados em 24, 48, 72 e 96 horas. Em seguida, separaram-se os dias de precipitação com ocorrências de deslizamento. Assim, foram obtidos dois conjuntos de dados: o primeiro contendo as precipitações acumuladas em um, dois, três e quatro dias, sendo esses resultados considerando o registro de chuva, e o segundo, apenas para os dias de ocorrência. Neste estudo, foram testados no máximo 4 dias consecutivos de precipitação, buscando investigar a importância da ocorrência de chuvas intensas em períodos curtos, para a deflagração de deslizamento, visto que a ocorrência desse tipo de episódio de precipitação é bastante frequente na estação chuvosa do Grande $A B C$ Paulista (VALVERDE; CARDOSO, 2012).

Foram gerados diferentes diagramas de dispersão dos dados de precipitação acumulada em um dia, comparado com a precipitação acumulada em dois, três e quatro dias, considerando diferentes critérios de limites de precipitação. $\mathrm{O}$ ajuste dessa relação é denominado envoltórias de deslizamento, conforme Tatizana et al. (1987 a, b), cuja curva traçada que melhor separa os registros de deslizamentos pode ser extraída através da seguinte expressão:

$$
I(A c)=K \times(A c)^{-b}
$$

$\mathrm{I}=$ Intensidade horária; $\mathrm{Ac}=$ acumulada de chuva dos 4, 3 ou 2 dias anteriores ao dia do evento; $\mathrm{Ke} \mathrm{b}=$ constantes de relação geométrica.

Os valores de $\mathrm{Ke} \mathrm{b}$ foram definidos automaticamente pelo software utilizado (Excel) através do Método dos Mínimos Quadrados, o qual ajustou a linha de tendência às curvas exponenciais. Considerou-se neste trabalho apenas dados de precipitação acumulada diária, portanto, o valor da Intensidade horária traçada no gráfico refere-se ao acumulado das 24 horas anteriores.

No método aplicado por Tatizana et al. (1987 a, b), foram consideradas ocorrências de deslizamentos associadas a, no mínimo, os seguintes acumulados de precipitação: $100 \mathrm{~mm}$ em um dia, ou $150 \mathrm{~mm}$ em 2 dias, ou $200 \mathrm{~mm}$ em 3 dias consecutivos. No entanto, devido aos valores da climatologia local e da média de ocorrências de deslizamentos, foi estabelecido para este caso de estudo outros três critérios, descritos pela Tabela 1. Esta tabela mostra os limiares de precipitação em que, abaixo dos quais, os eventos de deslizamentos não foram considerados na análise.

Tabela 1 - Critérios de Precipitação Propostos

\begin{tabular}{|ccccc|}
\hline \multicolumn{5}{c|}{ Precipitação $(\mathbf{m m})$} \\
\hline Critério & 1 Dia & 2 Dias & 3 Dias & 4 dias \\
\hline $\mathbf{1}$ & 35 & 50 & 70 & 90 \\
\hline $\mathbf{2}$ & 45 & 60 & 80 & 110 \\
\hline $\mathbf{3}$ & 50 & 80 & 120 & 150 \\
\hline
\end{tabular}

Para a validação da curva ajustada, foi calculado o coeficiente de determinação $\mathrm{R}^{2}$, que corresponde ao quadrado do coeficiente de correlação, o qual indica uma melhor medição da qualidade do ajuste da curva exponencial quando assume valores mais próximos de 1 .

\subsection{Resultados}

A Tabela 2 (segunda coluna) e as Figuras 2 e 3 apresentam os resultados obtidos através da análise da média dos acumulados mensais de precipitação para cada mês, no período de 2003 a 2012, assim como os limiares quantílicos de precipitação diária, considerando apenas os dias que ocorreram precipitação.

É possível identificar a marca da sazonalidade presente na região, apresentando os meses de dezembro, janeiro e fevereiro como os mais chuvosos (Figura 2). Através da análise dos quantis, torna-se evidente as diferenças entre os limiares associados às diferentes categorias de precipitação ao longo do ano, principalmente para categorias de precipitação acima do normal (Figura 3).

Os meses que apresentaram os maiores valores de precipitação para as categorias normal, chuvosa e muito chuvosa estão diretamente associadas aos meses mais chuvosos, ou seja, dezembro, janeiro e fevereiro. Nesses meses também ocorrem maiores variabilidades na precipitação (valores extremos distantes da média), o que pode ser observado através de maiores diferenças entre os limiares quantílicos para as diferentes categorias de precipitação, com destaque para janeiro (Tabela 2 e Figuras 2 e 3).

A partir da aplicação dos critérios de precipitação 
propostos, através dos limiares de precipitação acumulada diária, para 1, 2, 3 e 4 dias, de acordo com a Tabela 1, foram gerados gráficos de envoltórias para cada critério considerado (Figuras 4 a 6). Em cada uma das figuras, os pontos azuis apresentam todos os eventos de precipitação sem escorregamento, e os pontos vermelhos destacam os eventos de precipitação ocorridos em dias com registro de deslizamento na região estudada.

Foram considerados, no total, 940 dados de dias com chuva, que foi reduzido diante dos limites estabelecidos por cada critério (Tabela 1). De acordo com os dados da Defesa Civil do Município, no período de 2003 a 2012 houve 241 dias com ocorrências de deslizamentos na região estudada, independente da ocorrência ou não de precipitação no dia.

Tabela 2 - Médias da precipitação acumulada mensal (coluna 2) e valores dos seguintes limiares quantílicos de precipitação diária: 0,$35 ; 0,65$; e 0,85 , para cada mês do ano, no período de 2003 a 2012

\begin{tabular}{|c|c|c|c|c|c|c|}
\hline & $\begin{array}{c}\text { Média } \\
\text { acumulado } \\
\text { mensal }\end{array}$ & \multicolumn{2}{|c|}{ Normal } & \multicolumn{2}{c|}{ Chuvoso } & $\begin{array}{c}\text { Muito } \\
\text { Chuvoso } \\
(0,35<q \leq 0,65)\end{array}$ \\
\hline Janeiro & 319,77 & 5,00 & 15,60 & $15,65<q \leq 0,85)$ & 35,00 & 35,00 \\
\hline Fevereiro & 166,56 & 2,82 & 10,78 & 10,78 & 26,69 & 26,69 \\
\hline Março & 120,90 & 2,70 & 9,46 & 9,46 & 22,86 & 22,86 \\
\hline Abril & 64,75 & 2,30 & 6,52 & 6,52 & 13,47 & 13,47 \\
\hline Maio & 75,03 & 3,00 & 7,52 & 7,52 & 12,63 & 12,63 \\
\hline Junho & 40,35 & 2,00 & 4,35 & 4,35 & 13,25 & 13,25 \\
\hline Julho & 66,53 & 3,66 & 9,04 & 9,04 & 19,83 & 19,83 \\
\hline Agosto & 35,86 & 1,37 & 5,14 & 5,14 & 17,38 & 17,38 \\
\hline Setembro & 65,14 & 1,80 & 8,26 & 8,26 & 17,04 & 17,04 \\
\hline Outubro & 113,91 & 2,34 & 8,50 & 8,50 & 18,68 & 18,68 \\
\hline Novembro & 132,95 & 2,78 & 10,10 & 10,10 & 26,70 & 26,70 \\
\hline Dezembro & 182,59 & 3,30 & 10,15 & 10,15 & 26,84 & 26,84 \\
\hline
\end{tabular}

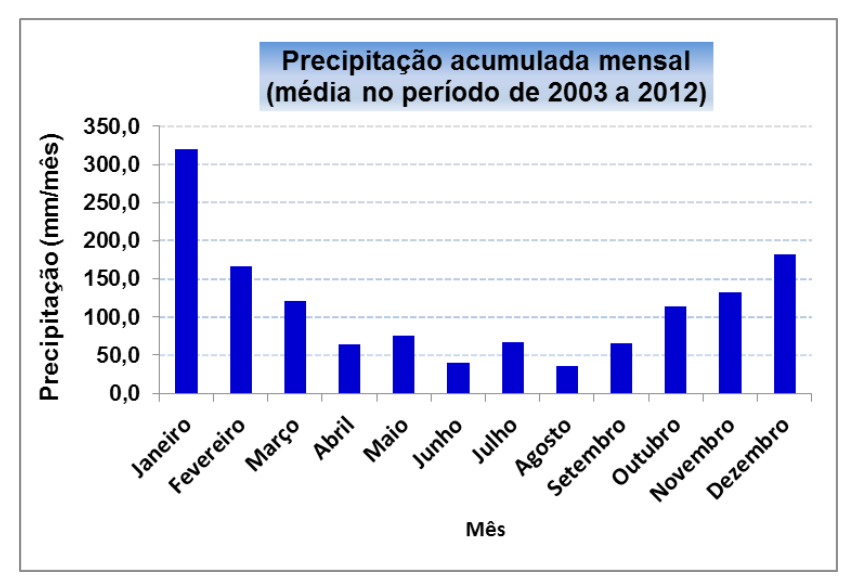

Figura 2 - Precipitação acumulada mensal, média no período de 2003 a 2012

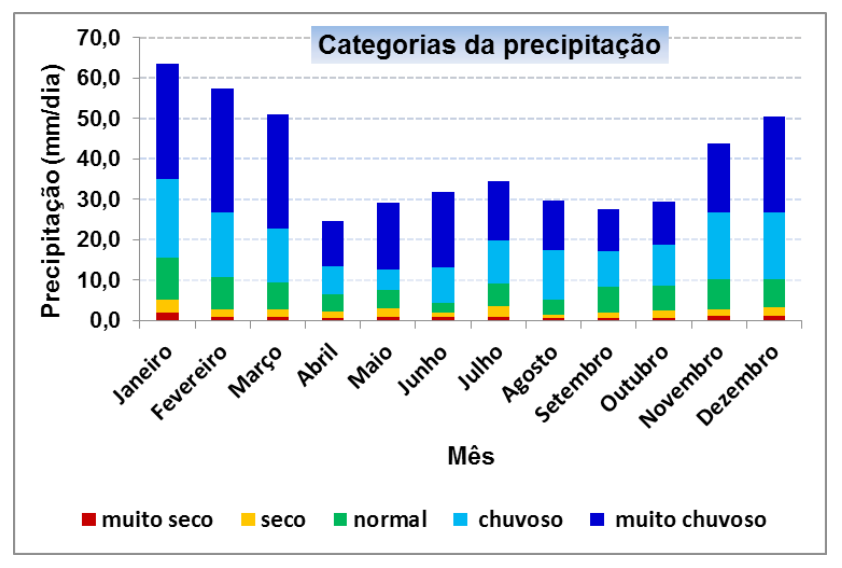

Figura 3 - Faixas das categorias de precipitação diária (muito seco, seco, normal, chuvoso e muito chuvoso), resultantes dos limiares quantílicos para cada mês do ano, no período de 2003 a 2012

O Critério 1 apresentou 69 dias com ocorrências de deslizamentos, combinando os acumulados de precipitação de 1 e 2 dias, 66 dias de ocorrências, para 1 e 3 dias e 52 dias para 1 e 4 dias. No caso do critério 2, foram 54 dias com ocorrências de deslizamentos para o acumulado de 1 e 2 dias, 51 dias para 1 e 3 dias, e 39 para 1 e 4 dias. O último critério, mais restritivo, apresentou 35 ocorrências de deslizamento na combinação dos acumulados de precipitação de 1 e 2 dias, 32 ocorrências para o caso de 1 e 3 dias, e 27 dias de ocorrências de deslizamentos para 1 e 4 dias.

Através dos valores de $\mathrm{R}^{2}$ e da visualização das curvas ajustadas, envoltórias de deslizamento, pôde ser detectado o melhor critério de ajuste que, no caso estudado, indica o percentual da variação dos valores de precipitação de um dia em relação à variação da precipitação acumulada nos dias anteriores. Portanto, quanto mais próximo de 1 for o valor de $\mathrm{R}^{2}$, melhor o ajuste da curva.

Dentre todas as envoltórias geradas para cada critério (Tabela 1), de um modo geral as que apresentaram os menores valores do coeficiente de determinação $\left(R^{2}\right)$ foram para os casos de comparação do acumulado de 1 dia com 2 dias, apresentados na Figura 4 , sendo $R^{2}$ igual a 0,20, 0,28 e 0,40 para o critério 1 ( 1 dia, $35 \mathrm{~mm}$ e 2 dias, $50 \mathrm{~mm}$ ), critério 2 ( 1 dia, $45 \mathrm{~mm}$ e 2 dias, $60 \mathrm{~mm}$ ) e critério 3 ( 1 dia, $50 \mathrm{~mm}$ e 2 dias, $80 \mathrm{~mm}$ ), respectivamente, onde o último apresentou o melhor resultado.

Considerando as envoltórias da comparação de 1 dia com 3 dias de precipitação acumulada, uma representativa melhora foi observada, identificada na Figura 5, sendo os valores de $\mathrm{R}^{2} 0,34,0,38$ e 0,52 para o critério 1 ( 1 dia, $35 \mathrm{~mm}$ e 3 dias, $70 \mathrm{~mm}$ ), critério 2 (1 dia, $45 \mathrm{~mm}$ e 3 dias, $80 \mathrm{~mm}$ ) e critério 3 ( 1 dia, $50 \mathrm{~mm}$ e 3 dias, $120 \mathrm{~mm}$ ), respectivamente. Ressalta-se que o critério utilizado pela Defesa Civil do município de SBC para estabelecer o estado de atenção é chuva acumulada 
em 72 horas (3 dias) de $80 \mathrm{~mm}$, igualmente ao critério 2 deste estudo, que indica bom resultado e boa aplicação para a atuação do Plano Preventivo, por não ser muito restritivo e, assim, minimizar o risco à população.

Os resultados para os gráficos de envoltórias de comparação de 1 e 4 dias de precipitação acumulada estão apresentados na Figura 6, com $R^{2}$ de 0,44, 0,50 e 0,56 para o critério 1 (1 dia, $35 \mathrm{~mm}$ e 4 dias, $90 \mathrm{~mm}$ ), critério 2 (1 dia, $45 \mathrm{~mm}$ e 4 dias, $110 \mathrm{~mm}$ ) e critério 3 (1 dia, $50 \mathrm{~mm}$ e 4 dias, $150 \mathrm{~mm}$ ), respectivamente. Estas envoltórias de 4 dias apresentaram os melhores resultados. Em termos empíricos, o terceiro critério foi o melhor identificado, o qual apresenta os valores mais restritivos, com altos limites de precipitação. Ao comparar com outros estudos, como Soares (2006), que obteve um $R^{2}$ de 0,54 para o acumulado de 4 dias antecedentes com a precipitação de 24 horas para Angra dos Reis - RJ, os valores do coeficiente de determinação obtidos no último caso são considerados significativos.

Portanto, no presente estudo, realizado para São Bernardo do Campo - SP, a equação abaixo (Eq. 2) representa a curva que se mostrou mais adequada para aplicação em um esquema de previsão de deslizamentos no município, a qual indica que, mesmo não havendo chuvas nos dias anteriores $(x=0)$, uma precipitação diária acima de $100 \mathrm{~mm}$ já é suficiente para o desencadeamento de movimentos de massa.

$$
y=106,18 e^{-0,011 x}
$$

Sendo $y$ a precipitação acumulada em 1 dia, e $x$ a precipitação acumulada em 4 dias.

De acordo com a Tabela 2, esse total de precipitação corresponde a aproximadamente o que chove no mês de outubro inteiro ou a um terço do que chove em janeiro (mês mais chuvoso) nessa região. Além disso, seria considerado um caso muito chuvoso, pois no período estudado não há registro diário desse total de precipitação ocorrido em um único dia na cidade de SBC, mesmo no mês mais chuvoso (Figura 3). Em termos de precipitação, torna-se evidente a importância da ocorrência de chuvas em dias anteriores ao de ocorrência do deslizamento, sendo este um fator que não pode ser desconsiderado nas análises de ricos.

Em adição, é necessário ressaltar que nem sempre foi possível encontrar valores de precipitação bem definidos para a ocorrência de deslizamentos. Nesta aplicação isso se deve, principalmente, ao fato de que o desencadeamento de movimentos de massa nesta região não está ligado apenas à precipitação, a seus extremos e à sazonalidade climática, mas também às atividades antrópicas, que não devem ser desconsideradas. $\mathrm{O}$ uso do solo interfere nos processos geodinâmicos, desde as características da ocupação em áreas de risco, lançamento de lixo, entulho e água servida, aterros e cortes em taludes, entre outras interações do homem com o meio físico, que favorecem a ocorrência de movimentos de massa.
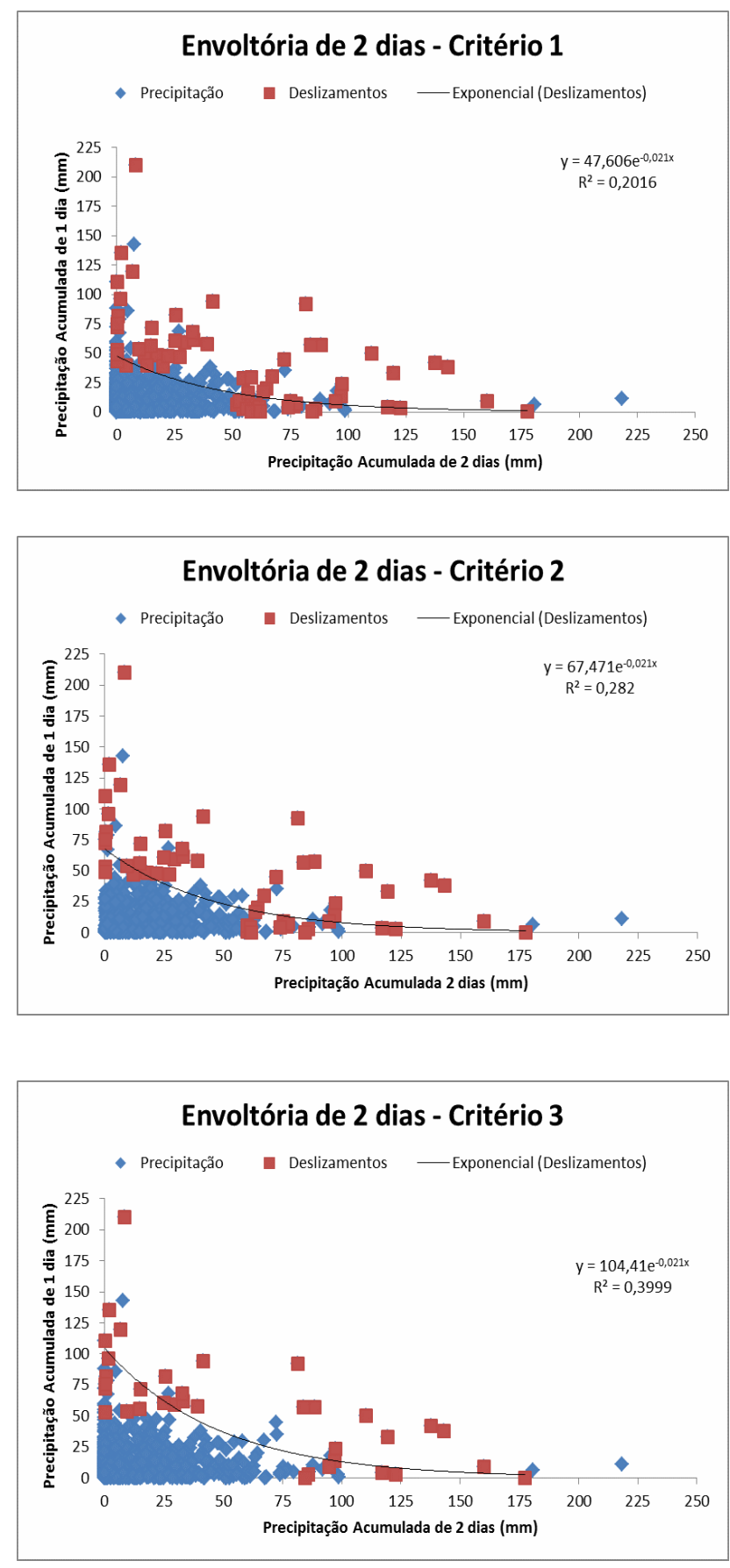

Figura 4 - Envoltórias de precipitação acumulada de 2 dias para o Critério 1, 2 e 3, respectivamente. Em azul destacam-se os eventos de chuva diária, e em vermelho os eventos de chuva em dias com ocorrência de deslizamento 

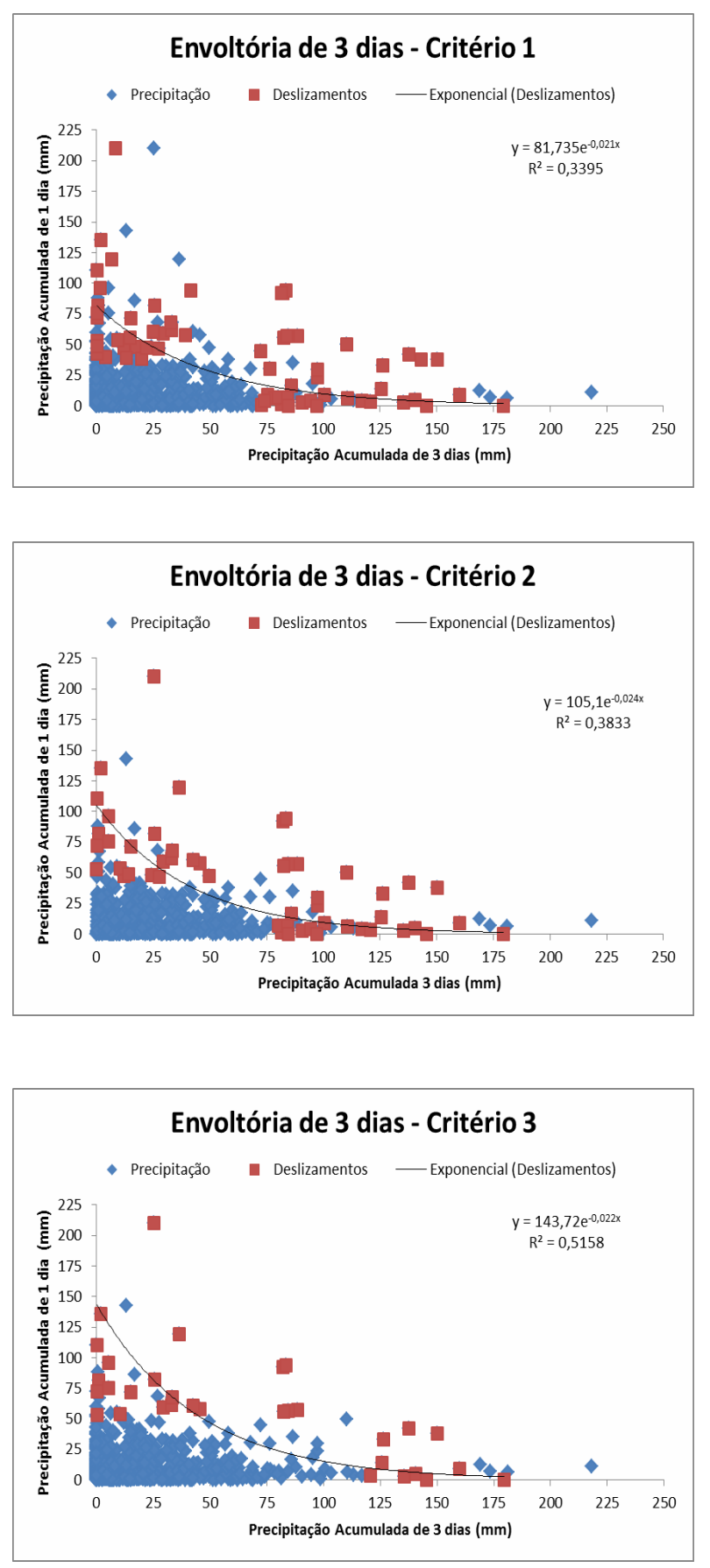

Figura 5 - Envoltórias de precipitação acumulada de 3 dias para o Critério 1, 2 e 3, respectivamente. Em azul destacam-se os eventos de chuva diária, e em vermelho os eventos de chuva em dias com ocorrência de deslizamento
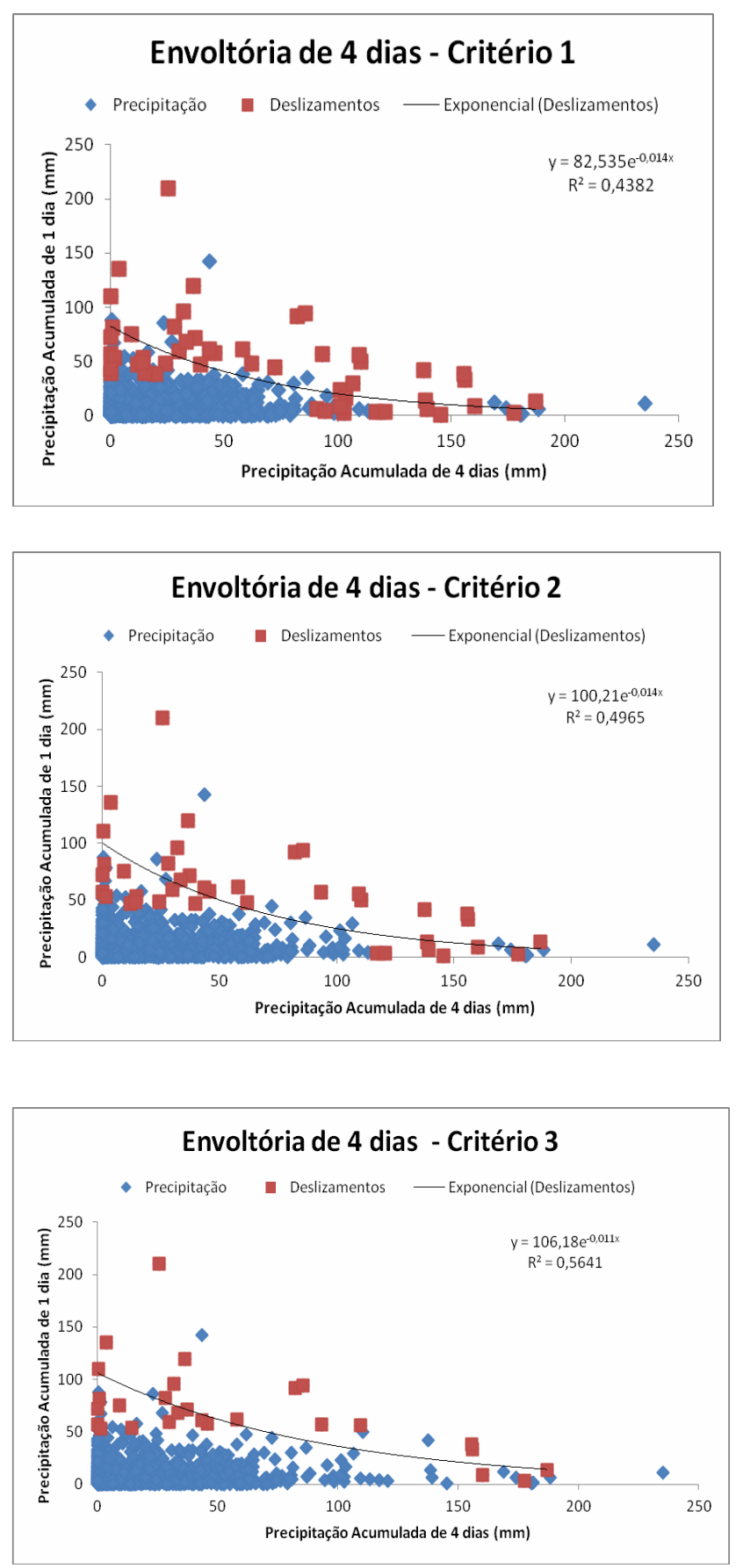

Figura 6 - Envoltórias de precipitação acumulada de 4 dias para o Critério 1, 2 e 3, respectivamente. Em azul destacam-se os eventos de chuva diária, e em vermelho os eventos de chuva em dias com ocorrência de deslizamento 
A análise da função e dos gráficos permite concluir que, quanto maior for o acumulado de chuvas, que reflete em um maior o grau de saturação do solo, menores intensidades pluviométricas horárias são suficientes para desencadear os escorregamentos. Eventos de chuva contínua com aumento de intensidade do meio ao fim do episódio representam grande risco de desencadeamento de deslizamentos, assim como os grandes desastres advêm principalmente de anomalias na distribuição de chuvas (TATIZANA et al., 1987 a, b) e geração de chuvas convectivas, com alto acumulado anterior. Isso pode ser justificado pelo aumento do grau de saturação do solo e, consequentemente, pela redução dos parâmetros de resistência (coesão e ângulo de atrito).

Observa-se que, quanto mais restritivo o critério, melhor o resultado obtido. É necessário considerar que esse fato não se deve apenas ao grau de saturação do solo, mas também à questão de representatividade estatística, visto que reduz os casos de dias com chuva e deslizamento, simplificando o ajuste da curva. A amplitude dos dados existentes com presença de deslizamento a partir de determinado valor vai diminuindo rapidamente conforme esse limiar aumenta.

Estes resultados podem auxiliar em ferramentas de previsão de deslizamentos, propondo valores de precipitação a partir do qual podem causar eventos de deslizamentos. No entanto, é comum em áreas urbanas ocorrerem eventos geodinamicos por inteferencia antropica, como problemas no sistema de drenagem e alta alteração do perfil geomorfologico natural.

\section{Conclusões}

No estudo para a definição de melhor ajuste da envoltória de deslizamento, foram avaliados três critérios, e observou-se que o melhor ajuste foi alcançado para o caso mais restritivo, limites mais altos de precipitação. Quanto mais restritivo o critério utilizado, melhores os resultados alcançados, ao associar deslizamentos somente com precipitação.

O modelo empírico utilizado que se mostrou mais eficaz foi o do critério $3(50 \mathrm{~mm}$ em 1 dia, $80 \mathrm{~mm}$ em dois dias, $120 \mathrm{~mm}$ em três dias e $150 \mathrm{~mm}$ em quatro dias), para a envoltória do acumulado de quatro dias consecutivos, com um $\mathrm{R}^{2}$ de 0,56 , que representa bem a divisão dos eventos de deslizamentos.

Além disso, a equação que melhor representa a curva adequada para um esquema de previsão de deslizamentos no município indica que, mesmo não havendo precipitação acumulada nos dias anteriores, uma precipitação diária acima de $100 \mathrm{~mm}$ já é suficiente para o desencadeamento de movimentos de massa, o que pode ocorrer em dias quentes, devido às chuvas convectivas. No entanto, em termos de precipitação, deve-se levar em conta a ocorrência de precipitações em dias anteriores, pois, neste caso, não são necessários eventos muito chuvosos para se relacionar aos casos de deslizamentos.

Os resultados também mostraram que nem sempre é possível encontrar valores de precipitação bem definidos para o desencadeamento de deslizamentos. Sendo assim, vale ressaltar que, por tratar-se de área urbana, há grande interferência antrópica que pode potencializar a ocorrência de deslizamentos, sendo a precipitação um dos fatores.

\section{Referências}

CASTRO J.C. Pluviosidade e Movimento de Massa nas Encosta de Ouro Preto.2006. Dissertação (Mestrado em Engenharia Civil) - Escola de Minas, Universidade Federal de Ouro Preto. Ouro Preto, 2006.

ELBACHÁ, T. A. Estudo da Estabilidade de Encostas em Áreas pauperizadas de Salvador. Salvador: UFBA, 1992.

FACETO, M. C. R. et al. Relação entre a Precipitação e a Ocorrência de Deslizamentos no Município de São Bernardo do Campo - SP. Santo André: UFABC, 2012.

GEO-RIO. Plataforma Georisc. Disponível em: $<$ http://georisc.les.inf.puc-rio.br/PortalGeoRisc/ geoRiscDesktopManual.html>. Acesso em 19/08/2013.

GUIDICINI, G. e IWASA, O.Y. Ensaio de Correlação entre Pluviometria e Deslizamentos em Meio Tropical Úmido. In: Simpósio Landslides and other Mass Moviment da IAEG, 1977, Praga, Publicação 1080 IPT, 1976.

IDE, F. S. Deslizamento, Meteorologia e Precipitação: uma Proposta de método de investigação para Prevenção e Monitoramento de Riscos, Aplicado em Campinas/SP" M.Sc., dissertação - Instituto de Pesquisas Tecnológicas (IPT) do Estado de São Paulo, 2005.

INSTITUTO DE PESQUISAS TECNOLÓGICAS DO ESTADO DE SÃO PAULO - IPT. Subsídios do meio físico ao planejamento e à gestão do uso e ocupação do solo no município de São Bernardo do Campo, SP: Carta geotécnica e mapa de localização de áreas de risco de escorregamento. Relatório IPT nº 40 927/99 São Paulo, 1999. 64 p.

PMSBC. Prefeitura Municipal de São Bernardo do Campo. Disponível em <http://www.saobernardo.sp.gov.br/>. Acesso em 01/06/2013.

SILVA DIAS, M. A. F.; DIAS, J.; SILVA DIAS, P. L.; FREITAS, ED. D.; CARVALHO, L. M. V. Changes in extreme daily rainfall for São Paulo, Brazil. Climatic Change, v. 116, p. 705-722, 2013. 
SOARES, Elenir Pereira. Caracterização da precipitação na região de Angra dos Reis e a sua relação com a ocorrência de deslizamentos de encostas. 145 p. Dissertação - Universidade Federal do Rio e Janeiro, COPPE. 2006.

TATIZANA, C., OGURA, A.T., CERRI, L.E.DA S., ROCHA, M.C.M. 1987a. Análise da correlação entre chuvas e escorregamentos aplicados às encostas da Serra do Mar, município de Cubatão. In: Congresso Brasileiro de Geologia de Engenharia, 5, 1987, São Paulo. Anais, São Paulo: ABGE. V.2, p.225-236.

TATIZANA, C., OGURA, A. T., CERRI, L. E. DA S., ROCHA, M. C. M. 1987b. Modelamento numérico de análise de correlação entre chuvas e escorregamentos aplicado às encostas da Serra do Mar, município de Cubatão. In: Congresso Brasileiro de Geologia de Engenharia, 5, 1987, São Paulo. Anais, São Paulo: ABGE. V.2, p.237-248.

VALVERDE, M. C.; CARDOSO, A. O. Eventos extremos de chuva associados com a ocorrência de enchentes na região do GrandeABC Paulista. In: XVII Congresso Brasileiro de Meteorologia, 2012, Gramado - RS. Anais do XVII Congresso Brasileiro de Meteorologia, 2012.

XAVIER, T. M. B. S.; XAVIER, A. F. S. 1987. Classificação e Monitoramento de Períodos Secos ou Chuvosos e Cálculo de Índices Pluviométricos para a Região Nordeste do Brasil. Rev. Brás. de Engenharia, vol. 5 ,n. 2 .. 